\title{
Chiari I Malformation Associated with Atlanto-Occipital Assimilation Presenting as Orthopnea and Cough Syncope: A Case Report and Review of Literature
}

\author{
Erwin Zeta Mangubat ${ }^{1}$ Tom Wilson ${ }^{1}$ Brian A. Mitchell ${ }^{1} \quad$ Richard W. Byrne ${ }^{1}$ \\ ${ }^{1}$ Department of Neurosurgery, Rush Professional Office Building, \\ Chicago, Illinois, United States \\ J Neurol Surg Rep 2014;75:e1-e4.

\begin{abstract}
Address for correspondence Erwin Zeta Mangubat, MD, MPH, Department of Neurosurgery, Rush Professional Office Building, 1725 W. Harrison Street, Suite 1115, Chicago, IL 60612, United States (e-mail: emangu1@gmail.com).
\end{abstract}

\begin{abstract}
Keywords

- Chiari I malformation

- atlanto-occipital assimilation

- cough syncope

- orthopnea

- central sleep apnea
\end{abstract}

\section{Introduction}

\section{Objective and Importance}

Chiari I malformation is a heterogeneous entity characterized by impaired cerebral spinal fluid (CSF) circulation at the level of the foramen magnum due to cerebellar tonsillar ectopia. The most frequent clinical presentation is headache or neck pain in adults and adolescents. Less common presentations include motor deficiencies, lower cranial nerve palsies, sensory dysfunctions, nystagmus, vertigo, ataxia, dysphagia, apnea, and snoring. Several cases of associated syncope have been reported as a presenting symptom caused by craniovertebral junction anatomic abnormalities. ${ }^{1-8}$

Advanced lesions associated with Chiari malformations and assimilation of the atlas may compress the medulla upon the clivus or cause temporary vascular occlusion resulting in brainstem ischemia and abnormalities in heart rate and respiration. ${ }^{9,10}$

received

April 20, 2013

accepted after revision

April 13, 2013

published online

December 12, 2013
We here present a patient harboring both a Chiari I malformation and atlanto-occipital assimilation contributing to cough syncope, orthopnea, and apnea.

\section{Clinical Presentation}

A 54-year-old man with history of sleep apnea presented to our neurosurgical clinic with complaints of progressive orthopnea and multiple episodes of cough syncope. The patient preferred to sleep upright to approximately 45 degrees for the past year; otherwise, he would wake up gasping for air. He was initially diagnosed with an anxiety disorder and was started on lorazepam, which failed to provide relief. Later, he was given the diagnosis of sleep apnea, which was unsuccessfully treated with continuous positive airway pressure (CPAP). These episodes of orthopnea progressed to the point where he would become apneic while awake in a horizontal position. His syncopal episodes were significant in that they
License terms

Stuttgart · New York

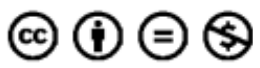



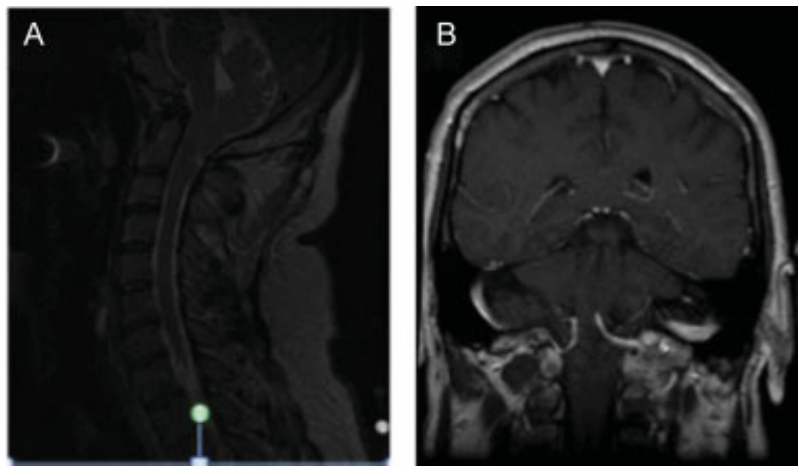

Fig. 1 T2- weighted sagittal (A) and T1-weighted contrasted coronal (B) magnetic resonance imaging (MRI) demonstrates a Chiari I malformation and assimilated atlas. The dimensions of the foramen magnum here measure $25 \mathrm{~mm}$ on anterior-posterior diameter and $35 \mathrm{~mm}$ on transverse diameter.

had resulted in motor vehicle accidents on two separate occasions. Initial syncopal workup at another institution included an extensive cardiopulmonary investigation that suggested a possible cardiac dysrhythmia. Subsequently, he underwent cardiac radiofrequency ablation. However, his syncopal episodes associated with coughing increased in frequency. Furthermore, he reported $1 \frac{1}{2}$ years of progressive imbalance, subjective quadriparesis, dysphagia, headache, and hoarseness.

His physical exam was significant for bilateral nystagmus on far lateral gaze, downbeat nystagmus on downward gaze, hoarse voice, and weak palatal elevation. The patient did have good strength throughout all muscle groups but was diffusely hyper-reflexic, though no pathologic reflexes could be elicited. He was also found to have some ataxia and difficulty with tandem gait.

The patient's magnetic resonance imaging (MRI) demonstrated a Chiari I malformation with associated assimilation of the atlas with the occipital bone, reducing the size of the

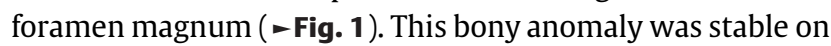
flexion and extension cervical films (-Fig. 2).

Our recommendation, in light of the patient's progressive and profound neurological symptoms, was for surgical de- compression the following morning after his evaluation in the clinic.

\section{Intervention}

The patient underwent a Chiari decompression, consisting of a suboccipital craniotomy, cervical level 2 laminectomy, and duraplasty with suturable DuraGen (Integra, Plainsboro, New Jersey, United States) and DuraSeal (Covidien, Mansfield, Massachusetts, United States).

The patient tolerated the procedure well without complications. Postoperatively, he continued to have some minimal nystagmus. However, his other neurological symptoms including orthopnea, strength, and hoarseness had significantly improved. On postoperative day 3 , the patient was taken back to the operating room for a wound revision for a CSF leak, which was repaired, proven by its resistance to a Valsalva maneuver. The rest of his stay was uncomplicated and he was discharged home on postoperative day 7 .

Between weeks 2 and 4 after discharge, the patient progressively developed headaches similar in character to his preoperative condition. An MRI was done at that time, which revealed a large pseudomeningocele and likely continued compression at the cervical 3 (C3) level (-Fig. 3). At that point, we had recommended extending the decompression via a C3 laminectomy, CSF leak repair, and placement of a lumbar drain. The patient tolerated the procedure well. The lumbar drain was removed after 48 hours. The patient's symptoms had resolved via the combined interventions, and he was discharged home on postoperative day 4 .

On 1-year follow-up, the patient was symptom free and had no abnormal neurological findings.

\section{Discussion}

Chiari I malformation and atlanto-occipital assimilation are both relatively rare conditions. The prevalence of a Chiari I malformation is estimated to be in the range of 1 per 1,000 to 1 per 5,000 individuals. ${ }^{11}$ The extent of atlanto-occipital assimilation varies from partial to total, which may account for the broad reported incidence from $0.08 \%$ to $3.6 \% .{ }^{12,13}$
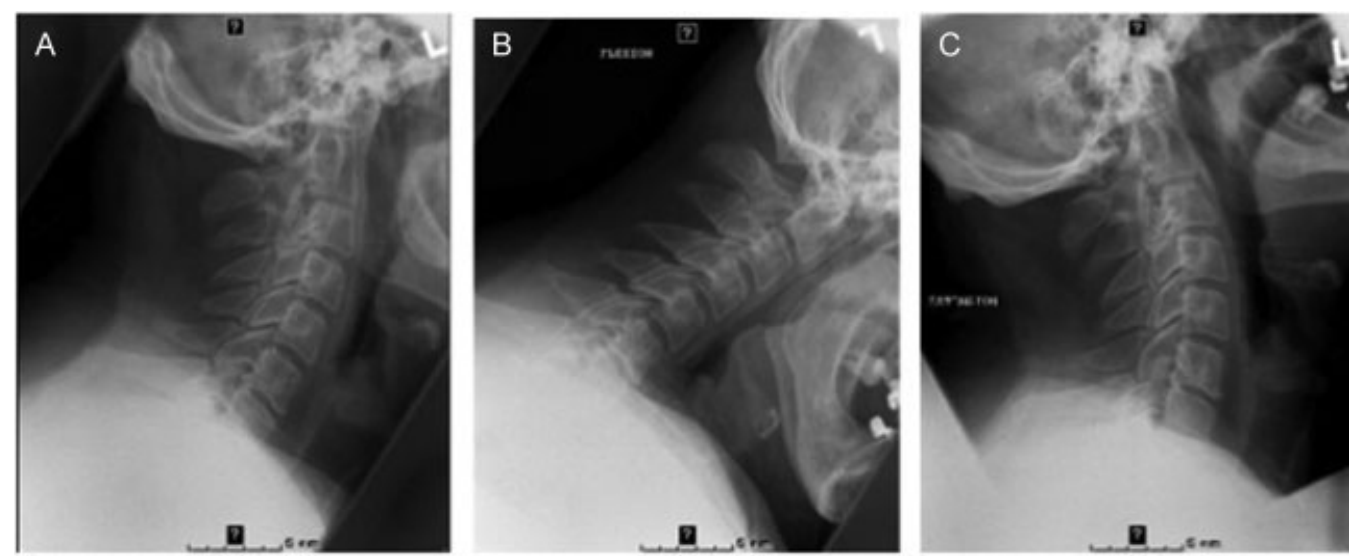

Fig. 2 Cervical X-rays in neutral (A), flexion (B), and extension (C) positions again demonstrate evidence of an atlanto-occipital assimilation. There appears to be no evidence of instability on flexion and extension films. 

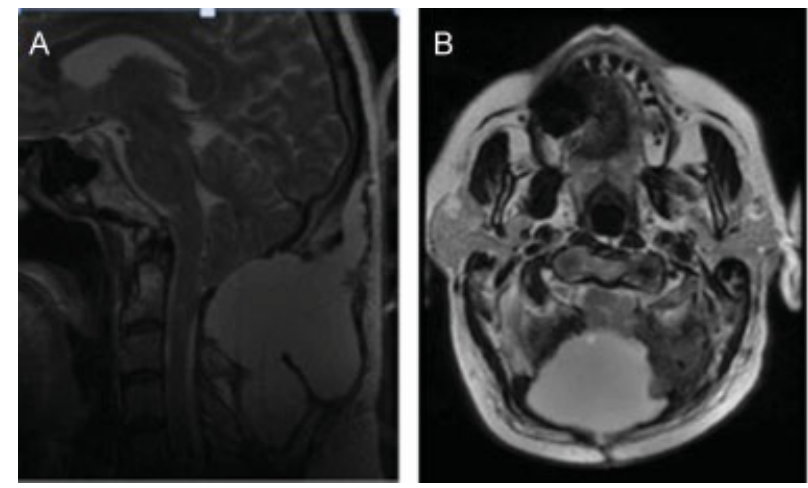

Fig. 3 One month postoperative sagittal (A) and axial (B) T2-weighted magnetic resonance imaging (MRI) demonstrating large pseudomeningocele at the site of the suboccipital craniectomy and upper cervical laminectomies extending into the posterior neck soft tissues, measuring approximately $7.7 \times 6 \mathrm{~cm}$ and causing mass effect on the inferiorly migrated cerebellar tonsils.

Chiari I malformation readily occurs in the presence of developmental bony anomalies. ${ }^{13,14}$ In a report of 364 cases of symptomatic Chiari I malformations, anomaly of the occipital bone-including occipitalization of the atlas, condylar hypoplasia, and other atypia of the occipital bone itselfdid not exceed 5.2\%. ${ }^{6}$ Conversely, some authors suggest that Chiari malformation exists in approximately $50 \%$ of patients with atlanto-occipital assimilation, generating possible CSF flow disorders. ${ }^{15}$

The occipital bone that forms the foramen magnum and vertebra originate in sclerotomes at the ventromedial portion of somites separated from the para-axial mesoderm. These structures are formed through complex differentiation processes that occur from gestational weeks 4 to $12 .{ }^{16}$ Maldevelopment may lead to craniovertebral junction abnormalities with varying degrees of superimposed bony anomalies, ${ }^{12,13,17-19}$ such as assimilation of the atlas, which is defined as a failure of segmentation between the fourth occipital sclerotome and the first spinal sclerotome. ${ }^{20,21}$ As a result, the volume of the posterior cranial fossa and foramen magnum is often reduced, which potentially produces distortion and compression of neural structures. ${ }^{22,23}$ Several morphometric analyses of the foramen magnum in dry skulls report an average anterior-posterior (AP) length to be 33.3 to $35.33 \mathrm{~mm}$ and the average transverse diameter to be 27.9 to $29.67 \mathrm{~mm} .{ }^{24-27}$ In our case study, the patient's AP length was $25 \mathrm{~mm}$ (approximately 25\% reduction) and his transverse diameter was $29 \mathrm{~mm}$.

In our case report, the patient unfortunately required two further surgeries to correct a likely continued CSF obstruction that was inadequately initially addressed. After both the initial suboccipital decompression/c2 laminectomy and the subsequent wound revision to repair the CSF leak, we were able to achieve a watertight closure proven by Valsalva maneuver. Therefore, we hypothesize that the profound narrowing associated with this rare anatomical combination of Chiari I malformation and atlanto- occipital assimilation may require a more extensive evaluation in regards to extent of decompression. Data provided by such studies as preoper- ative cine MRI (CSF pulsatile flow study) at the foramen magnum or intraoperative ultrasound to assess adequacy of CSF flow from the fourth ventricle may have prevented this postoperative complication.

Other anatomical considerations in managing patients with such bony anomalies include cognizance that the vertebral arteries may be malformed or pass abnormally and that the craniovertebral junction is a site inherently subject to instability. ${ }^{13}$ Therefore, in the presence of bony anomalies, it is important that management is determined on morphologic examination supplemented with a dynamic image-based evaluation of instability involving anterior and posterior flexion or horizontal rotation of the head. ${ }^{28}$

Classically, patients with Chiari malformation present with pain, weakness, sensory loss, dizziness, gait disturbances, or cranial nerve palsies. In patients with Chiari malformations, systematic studies have shown a prevalence of sleep respiratory disturbances between 59 and $70 \%{ }^{29,30}$ However, syncope is a relatively rare symptom and may occur with or without premonitory symptoms. Although the exact cause of Chiari I malformation-related syncope is not well understood, various pathophysiological mechanisms have been proposed that may occur with transient increases in intracranial pressure with Valsalva maneuvers, such as the following: vertebrobasilar artery compression, compression of the midbrain ascending reticular system, and compression of cardiorespiratory centers or their efferent and afferent autonomic pathways. $3,4,6,31,32$

Several isolated case reports of severe respiratory dysfunctions improved by decompressive surgery have been described. ${ }^{33,34}$ However, there are a few more systematic studies regarding the effects of surgery on sleep respiratory dysfunction in patients with craniovertebrobasilar junction malformations. One study evaluated 16 patients and found sleep apnea in 12 of them, with $48 \%$ of cases being central apnea. $^{35}$ Eight patients were surgically treated, and six underwent postoperative polysomnography, which indicated decreases in the patients' apnea index (defined as total number of apnea and hypopnea events divided by total sleep time) from $23.5 \pm 7.9$ to $9.8 \pm 6.6(p=0.1)$ and decreases in their central apnea index (CAI) (defined as number of sleep apneas divided by total sleep time) from $14.9 \pm 5.5$ to $1.3 \pm 0.6(p=0.03)$.

A similar study prospectively evaluated 25 patients with Chiari malformations who were then subjected to full-night polysomnography. ${ }^{36}$ Seventeen patients were diagnosed with sleep apnea, seven of which were found to have central apnea. After posterior fossa decompressive surgery, postoperative polysomnography demonstrated a decrease in apnea index from 26.68 to $12.98(p=0.06)$ and mean CAI from 13.81 to $1.68(p=0.01)$.

In patients with cervicomedullary anatomic abnormalities due to Chiari deformities, decompressive surgery may provide relief in the resulting autonomic dysfunction. Ireland et $\mathrm{al}^{32}$ evaluated both preoperative and postoperative postural changes in heart rate, heart rate variability, and blood pressure in nine patients with Chiari malformations and cough syncope. Their data suggested that patients with cervicomedullary anatomic 
abnormalities that may have abnormal autonomic control of heart rate return to a normal pattern after surgical palliation in conjunction with resolution of clinical symptoms. With decompression of the cervicomedullary junction, the CSF pathways are reformed, eliminating the pressure gradient between the cranium and spine and further impaction of the cerebellar tonsils.

\section{Conclusion}

Although Chiari I malformation-related syncope is rare, it should be considered amongst the differential diagnosis in working up a syncopal episode. Although the data are limited, these symptoms may respond well to decompressive surgery. Therefore, prompt diagnosis and treatment are essential. In cases concomitant with atlanto-occipital assimilation, the reduction in size of the foramen magnum may result in profound respiratory abnormalities that may require a more extensive decompression.

\section{References}

1 Aaronson DW, Rovner RN, Patterson R. Cough syncope: case presentation and review. J Allergy 1970;46(6):359-363

2 O'Doherty DS. Tussive syncope and its relation to epilepsy. Neurology 1953;3(1):16-21

3 Williams B. Cough headache due to craniospinal pressure dissociation. Arch Neurol 1980;37(4):226-230

4 Williams B. Chronic herniation of the hindbrain. Ann R Coll Surg Engl 1981;63(1):9-17

5 Prilipko O, Dehdashti AR, Zaim S, Seeck M. Orthostatic intolerance and syncope associated with Chiari type I malformation. J Neurol Neurosurg Psychiatry 2005;76(7):1034-1036

6 Milhorat TH, Chou MW, Trinidad EM, et al. Chiari I malformation redefined: clinical and radiographic findings for 364 symptomatic patients. Neurosurgery 1999;44(5):1005-1017

7 Weig SG, Buckthal PE, Choi SK, Zellem RT. Recurrent syncope as the presenting symptom of Arnold-Chiari malformation. Neurology 1991;41(10):1673-1674

8 Garland EM, Robertson D. Chiari I malformation as a cause of orthostatic intolerance symptoms: a media myth? Am J Med 2001;111(7):546-552

9 Nogués MA, Newman PK, Male VJ, Foster JB. Cardiovascular reflexes in syringomyelia. Brain 1982;105(Pt 4):835-849

10 List CF. Neurologic syndromes accompanying developmental anomalies of the occipital bone, atlas, and axis. Arch Neurol Psychiatr 1941;45:577-616

11 Speer MC, Enterline DS, Mehltretter L, et al. Review article: Chiari type I malformation with or without syringomyelia: prevalence and genetics. J Genet Couns 2003;12(4):297-311

12 Von Torklus D, Gehle W. The Upper Cervical Spine. London: Butterworths; 1972

13 Wackenheim A. Roentogen Diagnosis of the Craniovertebral Region. Berlin: Springer-Verlag; 1974

14 Caetano de Barros M, Farias W, Ataíde L, Lins S. Basilar impression and Arnold-Chiari malformation. A study of 66 cases. J Neurol Neurosurg Psychiatry 1968;31(6):596-605

15 Menezes AH, Ryken TC. Abnormalities of the craniovertebral junction. In: Cheek WR, Marlin AE, MacLone DG, Reigel DH, Walker ML, eds. Pediatric Neurosurgery, 3rd ed. Philadelphia: Saunders; 1994:139-158

16 Moore KL, Persaud TVN. The Developing Human: Clinically Oriented Embryology. 6th ed. Philadelphia: WB Saunders; 1998
17 Di Lorenzo N, Fortuna A, Guidetti B. Craniovertebral junction malformations. Clinicoradiological findings, long-term results, and surgical indications in 63 cases. J Neurosurg 1982;57(5): 603-608

18 Mesiwala AH, Shaffrey CI, Gruss JS, Ellenbogen RG. Atypical hemifacial microsomia associated with Chiari I malformation and syrinx: further evidence indicating that Chiari malformation is a disorder of paraxial mesoderm. Case report and review of the literature. J Neurosurg 2001;95(6): 1034-1039

19 Shapiro R, Robinson F. Anomalies of the craniovertebral border. AJR Am J Roentgenol 1976;127(2):281-287

20 MacRea DL, Barnum AS. Occipilaisation of the atlas. AJR Am J Roentgenol 1953;70:23-46

21 Menezes AH, VanGilder JC. Anomalies of the craniovertebral junction. In: Youmans J, ed. Neurological Surgery. 3rd ed. Philadelphia: Saunders; 1990:1359-1420

22 Nishikawa M, Sakamoto $H$, Hakuba $A$, Nakanishi $N$, Inoue Y. Pathogenesis of Chiari malformation: a morphometric study of the posterior cranial fossa. J Neurosurg 1997;86(1): 40-47

23 Vega A, Quintana F, Berciano J. Basichondrocranium anomalies in adult Chiari type I malformation: a morphometric study. J Neurol Sci 1990;99(2-3):137-145

24 Berge JK, Bergman RA. Variations in size and in symmetry of foramina of the human skull. Clin Anat 2001;14(6):406-413

25 Coin CG, Malkasian DR. Foramen magnum. In: Newton TH, Potts DG, eds. Radiology of the Skull and Brain: The Skull. St. Louis: Mosby; 1971:275-347

26 Lang J. Clinical Anatomy of the Posterior Cranial Fossa and Its Foramina. New York: Thieme; 1991

27 Muthukumar N, Swaminathan R, Venkatesh G, Bhanumathy SP. A morphometric analysis of the foramen magnum region as it relates to the transcondylar approach. Acta Neurochir (Wien) 2005; 147(8):889-895

28 Kagawa M, Jinnai T, Matsumoto Y, et al. Chiari I malformation accompanied by assimilation of the atlas, Klippel-Feil syndrome, and syringomyelia: case report. Surg Neurol 2006;65(5):497-502, discussion 502

29 Botelho RV, Bittencourt LR, Rotta JM, Tufik S. A prospective controlled study of sleep respiratory events in patients with craniovertebral junction malformation. J Neurosurg 2003;99(6): 1004-1009

30 Dauvilliers Y, Stal V, Abril B, et al. Chiari malformation and sleep related breathing disorders. J Neurol Neurosurg Psychiatry 2007;78(12):1344-1348

31 Garland EM, Robertson D. Chiari I malformation as a cause of orthostatic intolerance symptoms: a media myth? Am J Med 2001;111(7):546-552

32 Ireland PD, Mickelsen D, Rodenhouse TG, Bakos RS, Goldstein B. Evaluation of the autonomic cardiovascular response in ArnoldChiari deformities and cough syncope syndrome. Arch Neurol 1996;53(6):526-531

33 Botelho RV, Bittencourt LR, Rotta JM, Tufik S. Adult Chiari malformation and sleep apnoea. Neurosurg Rev 2005;28(3): 169-176

34 Zolty P, Sanders MH, Pollack IF. Chiari malformation and sleepdisordered breathing: a review of diagnostic and management issues. Sleep 2000;23(5):637-643

35 Flemons WW, Tsai W. Quality of life consequences of sleepdisordered breathing. J Allergy Clin Immunol 1997;99(2): S750-S756

36 Botelho RV, Bittencourt LR, Rotta JM, Tufik S. The effects of posterior fossa decompressive surgery in adult patients with Chiari malformation and sleep apnea. J Neurosurg 2010;112(4): 800-807 